\title{
Pyrolysis Biochar from Cellulosic Municipal Solid Waste as Adsorbent for Azo Dye Removal: Equilibrium Isotherms and Kinetics Analysis
}

\author{
Manu Agarwal, James Tardio, and S. Venkata Mohan
}

\begin{abstract}
Municipal solid waste (MSW) can have a negative impact on the environment and / or human health, if not properly managed. Though landfill is the most common method used to manage MSW, treating MSW using waste-toenergy (WtE) technologies is an option that is receiving increasing interest. Pyrolysis is a WtE technology that is capable of converting waste into products such as bio-gas, biooil and bio-char. Bio-char, which varies in composition based on the raw material pyrolysed, has the potential to be used as a fuel and as an applied material for catalysis or adsorption. In this work the removal of azo dye was investigated using biochar from pyrolysis of a cellulosic municipal solid waste. The bio-char was characterised using Scanning Electron Microscopy and Surface Area Analysis. The influence of pH on the dye removal was investigated over the range 4-7. The experimental data was analysed using four non-linear kinetic models (Pseudo first-order, pseudo second-order, Weber intraparticle diffusion and Elovich equation) and four non-linear isotherm models (Langmuir, Freundlich, Temkin and Sips), and ranked based on the statistical analysis tools in origin software. The dye removal kinetics most closely followed pseudo-first order kinetics whilst the adsorption isotherms were most closely fitted by the Temkin model over the $\mathrm{pH}$ range studied.
\end{abstract}

Index Terms-Azo dye, bio-char, municipal solid waste, water treatment.

\section{INTRODUCTION}

Management of municipal solid waste (MSW) is a challenge for all societies. Though landfill is the most commonly practiced way of managing MSW, treating MSW to produce valuable products [1] is receiving increased interest. Of the treatment options available pyrolysis has been identified as having significant potential as it produces lower emissions than combustion and gasification [2]. One of the known value added products from pyrolysis of waste containing organic matter is bio-char. Bio-char has a wide range of applications such as: a soil conditioner [3]-[5], adsorbent [6], electric double layer capacitor [7] and boiler

Manuscript received January 30, 2014; revised May 5, 2014.

Manu Agarwal is with Bioengineering and Environmental Centre (BEEC) and RMIT-IICT Research Centre, CSIR-Indian Institute of Chemical Technology (CSIR-IICT), Hyderabad-500 007, India; he is also with Centre for Advanced Materials and Industrial Chemistry, School of Applied Sciences, RMIT University, Melbourne VIC 3001, Australia.

James Tardio is with Centre for Advanced Materials and Industrial Chemistry, School of Applied Sciences, RMIT University, Melbourne VIC 3001, Australia.

S. Venkata Mohan is with Bioengineering and Environmental Centre (BEEC), CSIR-Indian Institute of Chemical Technology (CSIR-IICT), Hyderabad-500 007, India (e-mail: vmohan_s@yahoo.com). fuel for steam [8]. The similarities between bio-char and the raw products that are used to produce activated carbon indicate that bio-char also has potential for use as a source for activated carbon. One of the main uses of activated carbon is in the removal of pollutants from waste water. Azo dyes, which are used in the textile industries, are a common pollutant found in waste water [9], [10]. Azo dyes are known carcinogens which have a mutagenic effect on both aquatic life and humans. This property of dye forces the need of its removal from the wastewater before being discharged into water bodies. Colour removal from textile effluents is therefore an area of significant interest. Adsorption processes have shown promise as a practical and economic process; especially for colour removal [11]. Textile dye colour removal by adsorption onto activated carbon has proven to be highly efficient and reliable. However although colour removal by adsorption onto activated carbon is highly efficient, the overlying cost of the activated carbon and associated problems of regeneration and reuse warrants search for alternative low cost adsorbents [12]. Various materials derived from industrial waste materials, agricultural wastes, minerals, coal, soil, etc. have been widely investigated in this direction [11]-[15]. In the present work activated carbon was prepared using bio-char generated from pyrolysis of cellulose based municipal solid waste (CSW). The focal objective of this research was to investigate the potential of CSW as a raw material for producing an adsorbent that can be used for the removal of azo dye from aqueous solutions.

\section{MAterials AND MethodS}

\section{A. Materials}

The CSW was collected from a canteen in Hyderabad, India. The waste was dried under direct sunlight for three days to remove the unbound moisture and then shredded. C.I.Acid Black 10B (4-amino-5-hydroxy-3-[(4-nitrophenyl) azo]-6-(phenylazo)-2,7-naphthalene disulfonic acid disodium salt; $\mathrm{C}_{22}-\mathrm{H}_{14} \mathrm{~N}_{6} \mathrm{O}_{9} \mathrm{~S}_{2} \mathrm{Na}_{2}$; $\mathrm{MW}, 616.49$; CAS No. 1064-48-8), an azo dye (Fig. 1) belonging to acid application class was used for the dye removal tests. $\mathrm{KOH}$ and $\mathrm{HCl}$ where laboratory reagents procured from AVRA Industries Pvt. Ltd., India and Rankem Fine Chemicals Ltd., India respectively.

\section{B. Pyrolysis and Preparation of Adsorbent \\ 1) Preparation of bio-char}

Pyrolysis of CSW was conducted in a custom designed packed bed reactor [16] at $673 \mathrm{~K}-1073 \mathrm{~K}$ for three hours. 
A fixed amount of sample was packed in the reactor and placed inside the heater. The reactor was sparged with 99.99\% nitrogen gas to maintain inert atmosphere. The reactor was heated at a controlled rate $(12 \% \mathrm{~min})$ to the specified temperature and maintained for three hours.

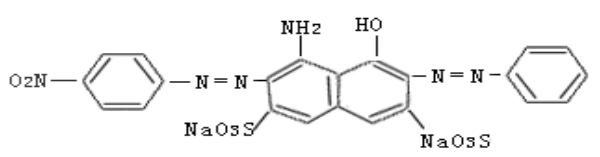

Fig. 1. Acid Black 10B azo dye.

\section{2) Preparation of adsorbent}

Bio-char was mixed with $\mathrm{KOH}$ in the ratio 1:4 by weight. The aforementioned mixture was placed in the reactor and fixed inside the heater. Pure nitrogen gas (99.99\%) was passed through the reactor to maintain an inert atmosphere. The reactor was heated at a controlled rate of $10 \% \mathrm{~min}$ to $1073 \mathrm{~K}$ and maintained for 5 hours thereafter. At the end of the process the reactor was allowed to cool and the resultant material was neutralized with $10 \% \mathrm{HCl}$. The material was washed with distilled water until the $\mathrm{pH}$ of the filtrate was 7.0. Finally, the prepared material (activated carbon (CSWAC)) was dried overnight at $333 \mathrm{~K}$.

\section{Adsorption Experiments}

The dye adsorption experiments were carried out in a batch reactor under the following conditions: $\mathrm{T}=303 \mathrm{~K}$; $\mathrm{pH}$ 4-7; activated carbon $=200 \mathrm{mg} / 100 \mathrm{~mL}$; acid black $10 \mathrm{~B}$ dye concentration solution $10 \mathrm{mg} / \mathrm{l}$. The reaction vessel agitated using a shaking incubator (Labtech) at $120 \mathrm{rpm}$ for one hour.

\section{Analysis}

SEM was conducted using a FEI Quanta SEM 200. Surface area was analysed using a Micromeritics ASAP 2010. Dye concentration was determined using a UV-VIS spectrophotometer (GE Genequant 1300).

\section{RESUlTS AND DISCUSSION}

\section{A. Characterization of Prepared Activated Carbon}

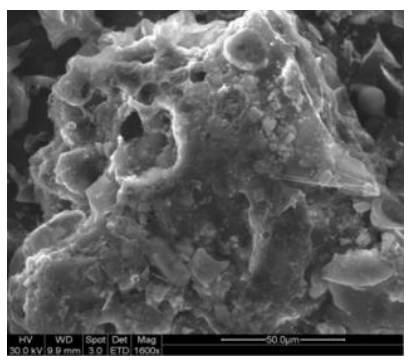

(a)

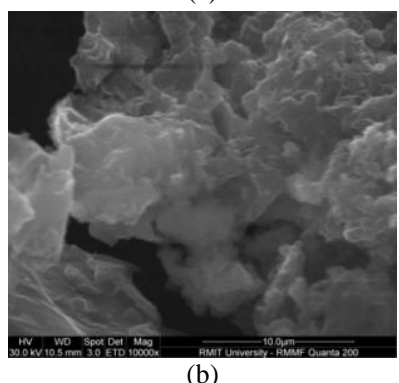

(b)

Fig. 2. SEM images of (a) Bio-char (b) Activated carbon.
The bio-chars produced at medium and high temperature were selected for studying the dye adsorption capacity. It was observed that the high temperature bio-char produced elemental sodium after treatment and so was not suitable for adsorption study. Hence, the bio-char produced from CSW at medium temperature was further studied. After the acid treatment $(10 \% \mathrm{HCl})$ of the bio-char from CSW it was observed that the CSW-AC yield was $93.55 \%$ by wt. The SEM images of bio-char and activated carbon were recorded (Fig. 2) and micropore surface area of the samples were 150.67 and $1237.73 \mathrm{~m}^{2} / \mathrm{g}$, respectively.

\section{B. Investigations on the Removal of Azo Dye (Acid Black 10B)}

Removal of Acid black-10B (azo dye) using activated carbon (prepared from bio char generated from kitchen vegetable waste) was investigated over a period of 60 minutes at four $\mathrm{pH}$ values $(4,5,6$ and 7$)$. The adsorption profiles obtained for these tests are shown in Fig. 3. The adsorption rate was relatively high up to $20 \mathrm{~min}(\mathrm{pH} 4$ : $0.093 \mathrm{mg} / \mathrm{g} / \mathrm{min} ; \mathrm{pH}$ 5: $0.1 \mathrm{mg} / \mathrm{g} / \mathrm{min} ; \mathrm{pH}$ 6: 0.125 $\mathrm{mg} / \mathrm{g} / \mathrm{min} ; \mathrm{pH}$ 7: $0.1 \mathrm{mg} / \mathrm{g} / \mathrm{min}$ ) and subsequently reduced with time (rates from $20-60$ minutes were as follows: $\mathrm{pH}$ 4: $0.0781 \mathrm{mg} / \mathrm{g} / \mathrm{min} ; \mathrm{pH}$ 5: $0.075 \mathrm{mg} / \mathrm{g} / \mathrm{min} ; \mathrm{pH}$ 6: 0.0625 $\mathrm{mg} / \mathrm{g} / \mathrm{min} ; \mathrm{pH} 7: 0.075 \mathrm{mg} / \mathrm{g} / \mathrm{min})$. For the tests conducted in the acidic $\mathrm{pH}$ range $100 \%$ adsorption capacity was achieved in $60 \mathrm{~min}$, whereas at neutral $\mathrm{pH}$ this was achieved in $50 \mathrm{~min}$. The higher adsorption rate initially could be attributed to the participation of active sites/functional group present on the surface while the adsorption rate later decreased due to more and more occupancy of these active sites.

\section{1) Sorption kinetics}

Linear forms of different kinetic models (intra-particle diffusion model [17], [18], the pseudo-first-order kinetic model, the pseudo-second-order kinetic model [19]-[21] and the Elovich equation) based on the aqueous phase concentration of sorbate were used to evaluate the sorption mechanism at the $\mathrm{pH}$ values investigated.

a) Kinetic models

Sorption rate can be estimated based on the pseudo-firstorder (Lagergren's equation) and pseudo-second order kinetic equations by assuming the dye-CSW-AC sorption process as a pseudo-chemical reaction [16], [21], [22] represented by equations 1 and 2 , respectively.

$$
\begin{aligned}
& d q_{t} / d t=K_{1}\left(q_{e}-q_{t}\right) \\
& d q_{t} / d t=K_{2}\left(q_{e}-q_{t}\right)^{2}
\end{aligned}
$$

where, $q_{e}(\mathrm{mg} / \mathrm{g})$ and $q_{t}(\mathrm{mg} / \mathrm{g})$ are adsorption capacities at equilibrium and time $t$, respectively and $K_{1}\left(\mathrm{~min}^{-1}\right)$ and $K_{2}$ $(\mathrm{g} / \mathrm{mg} / \mathrm{min})$ are the first and second order rate constants respectively. Pseudo first order and pseudo second order plots for CSW-AC showed a reasonably good fit using the experimental data obtained, with the $1^{\text {st }}$ order fits being slightly better (Fig. 4). The first and second order rate constants (Table I) for the sorption of azo dye from the aqueous phase by CSW-AC were obtained by the slope of 
the respective curves.
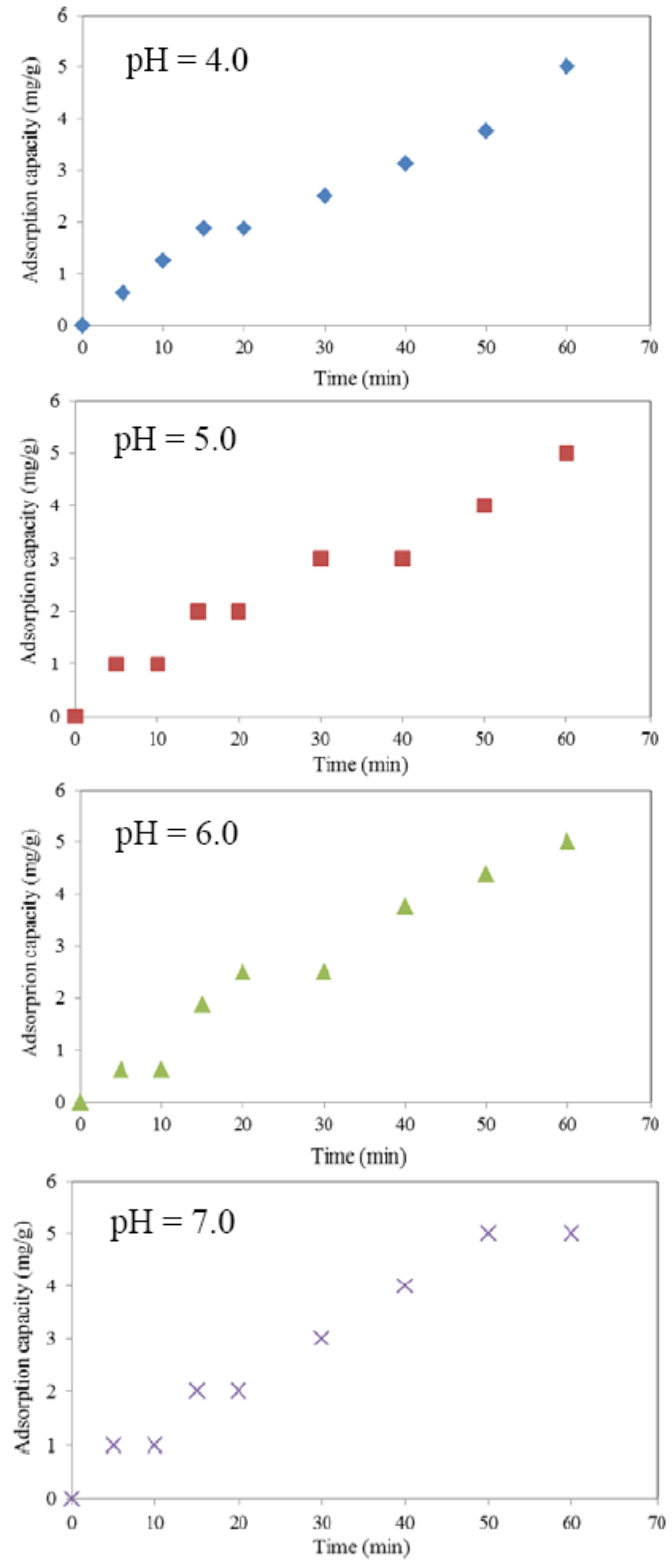

Fig. 3. Acid black $10 \mathrm{~B}$ dye sorption with CSW-AC as sorbent.
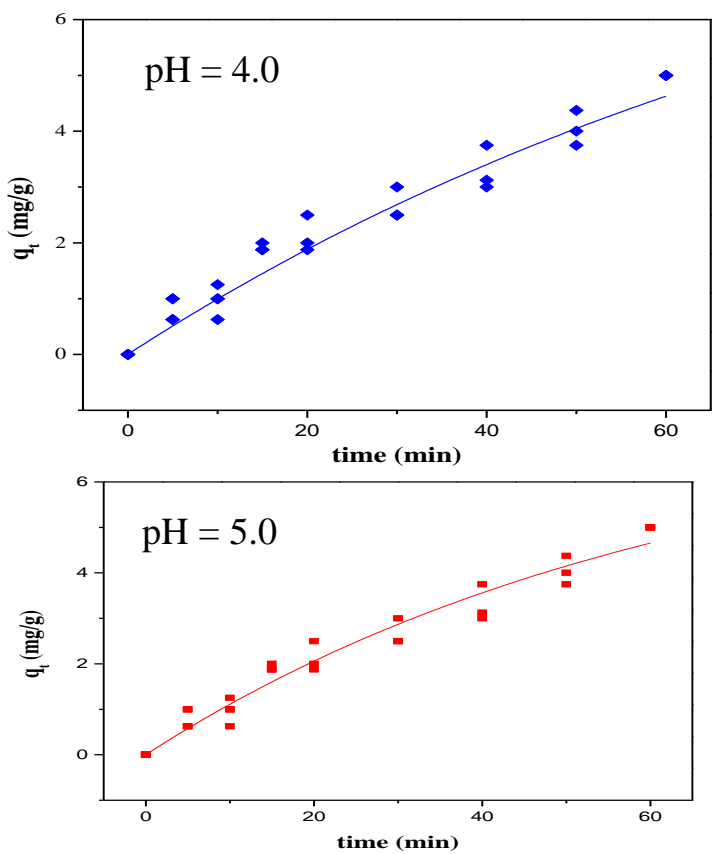
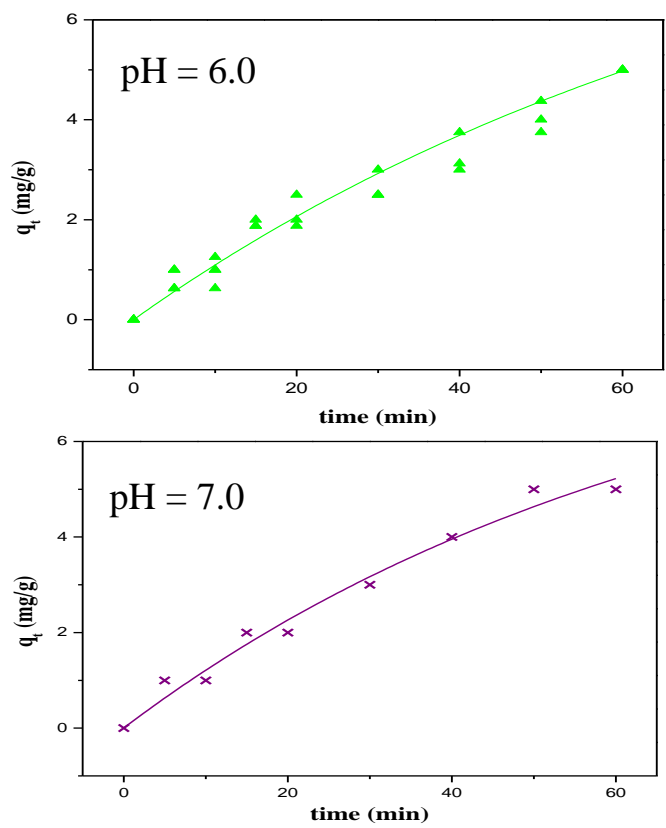

Fig. 4. Pseudo first order kinetic model.

b) Weber's intra-particle diffusion model

The intra-particle diffusion model is a single-resistance model derived from Fick's second law which can be expressed mathematically by equation 3 [11], [23].

$$
q_{t}=K_{p} t^{0.5}
$$

where, $K_{p}\left(\mathrm{mg} / \mathrm{g} \cdot \mathrm{min}^{0.5}\right)$ is the intra-particle diffusion rate constant. To fit the intra-particle diffusion model over the data the amounts of azo dye adsorbed per unit mass $\left(q_{t}\right)$ was plotted against the square root of contact time $\left(t^{0.5}\right)$. The intra-particle diffusion plot was observed to fit successfully for the systems at different $\mathrm{pH}$, and an increase in the intraparticle diffusion rate constant (Table I) was observed with increasing $\mathrm{pH}$. A straight-line plot that did not pass through the origin was noticed for the azo dye sorption system. This indicates some degree of boundary layer control which further shows that intra-particle diffusion is not the only rate-controlling step, but also other processes may control the rate of adsorption [19]-[23]. The intra-particle diffusion plot of azo dye sorption system indicates the complex nature involving both boundary layer and intra-particle diffusions with respect to initial azo dye concentration. The intraparticle diffusion model assumes that the diffusion (internal surface and pore diffusion) of sorbate molecules inside the adsorbent is rate limiting and the film diffusion is considered negligible [23], [24].

c) Elovich equation

The Elovich equation (Eq. 4) is a model used to describe irreversible chemisorption [25].

$$
d q_{t} / d t=a e^{-b q_{t}}
$$

where, $a$ (mg/g.min) is the initial adsorption rate. The Elovich equation parameters $a, b$ were calculated from $q_{t}$ vs $\ln t$ plots (Table I). The constants $a, b$ are related to the rate of chemisorption and the surface coverage, respectively [26]. Therefore, increase in the concentration of dye solution 
and mass of sorbent will increase the rate of adsorption. Also an increase in dye concentration or decrease in the mass of CSW-AC will reduce the available adsorption surface. The constant a (related to the rate of chemisorption) was observed to be highest at neutral $\mathrm{pH}$ supporting maximum sorption reached in $50 \mathrm{~min}$, which was $60 \mathrm{~min}$ with other $\mathrm{pH}$ conditions.

\section{d) Comparison of adsorption kinetics}

The parameters calculated by application of kinetic models over the experimental data were used to predict the effect of time on dye-CSW-AC adsorption system. Considering all the above results, the kinetics of dye adsorption over CSW-AC can be described best by pseudofirst order.

\begin{tabular}{|c|c|c|c|c|}
\hline & $\mathrm{pH}=4.0$ & $\mathrm{pH}=\mathbf{5 . 0}$ & $\mathrm{pH}=6.0$ & $\mathrm{pH}=7.0$ \\
\hline \multicolumn{5}{|l|}{ Pseudo-first order } \\
\hline$q_{e}(\mathrm{mg} / \mathrm{g})$ & 9.744 & 7.608 & 9.735 & 9.030 \\
\hline$K_{1}\left(\min ^{-1}\right)$ & $1.07 \mathrm{E}-2$ & $1.57 \mathrm{E}-2$ & $1.19 \mathrm{E}-2$ & $1.44 \mathrm{E}-2$ \\
\hline$R^{2}$ & 0.965 & 0.952 & 0.968 & 0.977 \\
\hline \multicolumn{5}{|l|}{ Pseudo-second order } \\
\hline$q_{e}(\mathrm{mg} / \mathrm{g})$ & 8.771 & 4.566 & 9.708 & 5.291 \\
\hline$K_{2}(\mathrm{~g} / \mathrm{mg} \cdot \min )$ & $1.7 \mathrm{E}-3$ & $1.04 \mathrm{E}-2$ & $1.2 \mathrm{E}-3$ & 7.4E-3 \\
\hline$R^{2}$ & 0.988 & 0.768 & 0.763 & 0.768 \\
\hline \multicolumn{5}{|c|}{$\begin{array}{l}\text { Weber's Intra-particle } \\
\text { diffusion model }\end{array}$} \\
\hline$K_{p}\left(\mathrm{mg} / \mathrm{g} \cdot \min ^{0.5}\right)$ & 0.612 & 0.613 & 0.685 & 0.709 \\
\hline$R^{2}$ & 0.936 & 0.938 & 0.927 & 0.940 \\
\hline SSE & 1.157 & 1.124 & 1.658 & 1.468 \\
\hline \multicolumn{5}{|l|}{ Elovich equation } \\
\hline$a$ (mg/g.min) & 0.352 & 0.386 & 0.356 & 0.402 \\
\hline$b(\mathrm{~g} / \mathrm{mg})$ & 0.641 & 0.651 & 0.549 & 0.551 \\
\hline$R^{2}$ & 0.884 & 0.867 & 0.911 & 0.890 \\
\hline
\end{tabular}

TABLE II: COMPARISON OF ADSORPTION ISOTHERM MODEL PARAMETERS

\begin{tabular}{|c|c|c|c|c|}
\hline & $\mathbf{p H}=\mathbf{4 . 0}$ & $\mathbf{p H}=\mathbf{5 . 0}$ & $\mathbf{p H}=\mathbf{6 . 0}$ & $\mathbf{p H}=\mathbf{7 . 0}$ \\
\hline Langmuir isotherm & & & & \\
\hline$q_{m l}(\mathrm{mg} / \mathrm{g})$ & 0.794 & 0.903 & 0.887 & 1.035 \\
\hline$b_{L}(\mathrm{mg} / \mathrm{l})$ & 0.414 & 0.531 & 0.783 & 0.581 \\
\hline$R_{L}$ & 0.194 & 0.158 & 0.113 & 0.146 \\
\hline$R^{2}$ & 0.432 & 0.355 & 0.337 & 0.533 \\
\hline Freundlich isotherm & & & & 5.731 \\
\hline$K_{F}\left((\mathrm{~m} / \mathrm{g}) /(\mathrm{mg} / \mathrm{l})^{\mathrm{N}}\right)$ & 6.896 & 6.566 & 6.302 & -1.406 \\
\hline$N$ & -1.230 & -1.303 & -1.206 & 0.885 \\
\hline $\mathrm{R}^{2}$ & 0.781 & 0.844 & 0.784 & -1228.250 \\
\hline Temkin isotherm & & & & 0.073 \\
\hline$b(\mathrm{~J} / \mathrm{mol})$ & -942.439 & -1027.382 & -1202.454 & 0.949 \\
\hline$K_{T}(1 / \mathrm{mg})$ & 0.086 & 0.081 & 0.076 & \\
\hline$R^{2}$ & 0.956 & 0.941 & 0.919 & $1.19 \mathrm{E}-3$ \\
\hline Sips isotherm & & & & -1.000 \\
\hline$q_{s}(\mathrm{mg} / \mathrm{g})$ & $1.575 \mathrm{E}-3$ & $1.557 \mathrm{E}-3$ & $3.98 \mathrm{E}-4$ & $4.48 \mathrm{E}-4$ \\
\hline$K_{s}\left((\mathrm{l} / \mathrm{mg})^{1 / \mathrm{m}}\right)$ & -0.998 & -0.999 & -0.999 & 0.496 \\
\hline $1 / \mathrm{m}$ & $1.28 \mathrm{E}-3$ & $8.36 \mathrm{E}-4$ & $2.57 \mathrm{E}-4$ & \\
\hline$R^{2}$ & 0.372 & 0.554 & 0.339 & \\
\hline
\end{tabular}

\section{2) Adsorption isotherms}

Equilibrium isotherm models express the relationship between the quantity of sorbate absorbed and the concentration in solution at equilibrium. The parameters derived from these equations and the underlying thermodynamic assumptions of these equilibrium isotherm models provide insight into the sorption mechanism and the surface properties and affinity of the sorbent. Equilibrium sorption models were employed to estimate sorption capacities of azo dye with CSW-AC as sorbent.

\section{a) Langmuir model}

The Langmuir isotherm is one of the most commonly used models describing the equilibrium concentration at the adsorbent surface $(q)$ and sorbate concentration in solution $(C)$ at a constant temperature. The Langmuir model [27], [28] can be represented by equation 5. The essential characteristic of the Langmuir isotherm can be expressed in terms of a dimensionless constant, separation factor $R_{L}$ (equation 6), which describes the type of isotherm. The values of $R_{L}$ indicate the type of isotherm to be unfavourable $\left(R_{L}>1\right)$, linear $\left(R_{L}=1\right)$, favourable $\left(0<R_{L}<1\right)$ and irreversible $\left(R_{L}=0\right)$.

$$
q=q_{m L} b_{L} C /\left(1+b_{L} C\right)
$$




$$
R_{L}=\left(1+b_{L} C_{0}\right)^{-1}
$$

where, $q_{m L}(\mu \mathrm{g} / \mathrm{g})$ and $b_{L}$ are the Langmuir parameters that represent the maximum sorption capacity and the site energy factor, respectively. A non-linear regression of sorption data for the azo dye-CSW-AC system was applied and the resulting Langmuir parameters for sorption capacity $\left(q_{m L}\right)$ calculated from the slope and intercept of the plot respectively (Table II). The Langmuir model for CSW-AC sorption system showed a poor fit. The values of $R_{L}$ for CSW-AC sorbent system represented that the azo dye sorption was favourable over the $\mathrm{pH}$ range.

\section{b) Freundlich model}

The Freundlich model, which is given in equation 7, is very similar to the Langmuir model [28], [29].

$$
q=K_{F} C^{N}
$$

where, $C(\mathrm{mg} / \mathrm{l})$ is the aqueous phase concentration, $q_{t}$ $(\mathrm{mg} / \mathrm{g})$ is the solid phase concentration, and $K_{F}$ $\left[(\mathrm{mg} / \mathrm{g}) /(\mathrm{mg} / \mathrm{l})^{N}\right]$ and $N$ are the Freundlich sorption coefficient and the Freundlich exponent, respectively. The Freundlich sorption coefficient $\left(K_{F}\right)$ for azo dye-CSW-AC system was calculated by fitting the sorption data using equation 7. The Freundlich model showed a good fit with the CSW-AC sorption system. It was observed that the $K_{F}$ (Table II) decreased with increasing $\mathrm{pH}$ while the Freundlich exponent was almost constant.

\section{c) Temkin model}

The Temkin isotherm assumes that the decrease in the heat of adsorption is linear and the adsorption is characterized by a uniform distribution of binding energies. The Tempkin model can be explained using equation 8 . [30].

$$
q_{t}=(R T / b) \ln \left(K_{T} C\right)
$$

where, $C(\mathrm{mg} / \mathrm{l})$ is the aqueous phase concentration, $\mathrm{q}_{\mathrm{t}}$ $(\mathrm{mg} / \mathrm{g})$ is the solid phase concentration, $K_{T}(1 / \mathrm{mg})$ is equilibrium binding constant, $b(\mathrm{~J} / \mathrm{mol})$ is related to heat of adsorption, $R$ is the gas constant $(8.314 \mathrm{~J} / \mathrm{mol} / \mathrm{K})$ and $T(\mathrm{~K})$ is the absolute temperature. The equilibrium binding constant $\left(K_{T}\right)$ for azo dye-CSW-AC system were calculated by fitting the sorption data in equation 8 (Fig. 5). It was observed that the $K_{T}$ value reduced while the $b$ value increased with $\mathrm{pH}$. The values of constant ' $b$ ' indicated that the heat of adsorption increased with increase in $\mathrm{pH}$ and hence the adsorption can possibly be improved by decreasing the temperature.

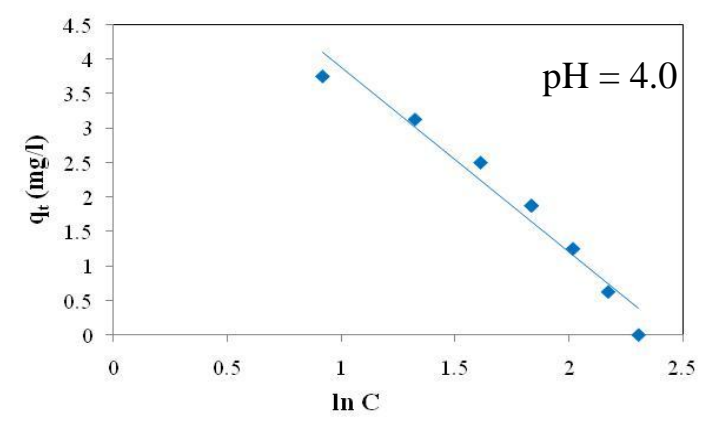

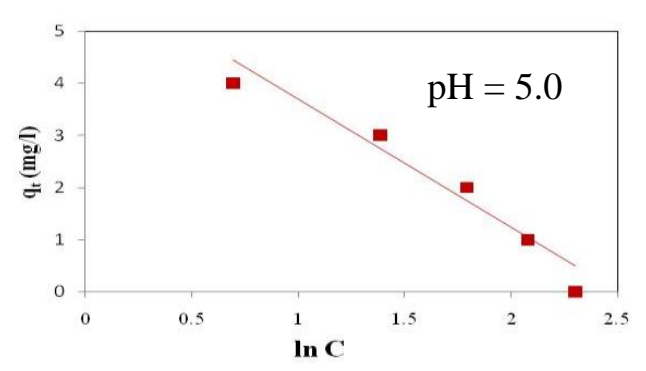
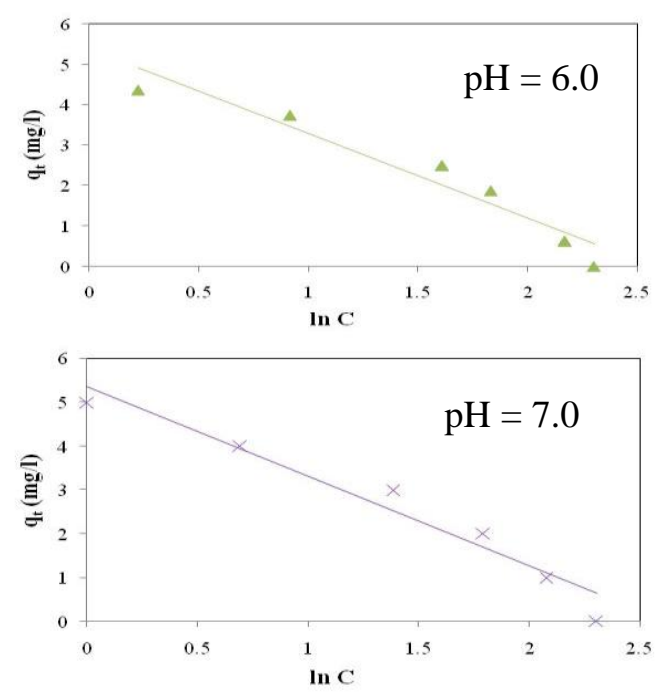

Fig. 5. Temkin adsorption equilibrium model.

\section{d) Sips model}

The Sips model (equation 9) [31] is a combination of the Langmuir and Freundlich models. At low sorbate concentrations it reduces to the Freundlich isotherm and at high concentrations it becomes the Langmuir model.

$$
q_{t}=q_{s} K_{s} C^{m^{-1}} /\left(1+K_{s} C^{m^{-1}}\right)
$$

where, $q_{s}(\mathrm{mg} / \mathrm{g})$ is monolayer adsorption capacity and $K_{s}$ is Sips constant related to energy of adsorption. A power fit over the sorption data for the dye-CSW-AC system was applied to calculate the parameters shown in Table II. The exponent $\mathrm{m}^{-1}$ (Table II) is close to zero, indicating the dyeCSW-AC system is more closely explained by the Freundlich model compared to the Langmuir model.

\section{e) Comparison of adsorption isotherms}

The constants derived by fitting the isotherms over the experimental data were used express relationship between the quantity of sorbate absorbed and the concentration in solution at equilibrium. Considering all the above results, the adsorption isotherm of dye-CSW-AC system can be best described by Temkin isotherm over the $\mathrm{pH}$ range.

\section{Conclusions}

Adsorption of acid black dye using activated carbon derived from the cellulose fraction of municipal solid waste was investigated. Four non-linear kinetic models and four non-linear isotherm models were used to investigate the experimental data and ranked based on the statistical analysis tools in origin software. The dye-CSW-AC system is best described by pseudo-first order. Also the equilibrium data fit the Temkin model well at all aqueous solution $\mathrm{pH}$. 


\section{ACKNOWLEDGEMENT}

Authors acknowledge the Director, CSIR-IICT for kind support and encouragement in carrying out this work. M.A. wishes to acknowledge the support of Director, CAMIC, RMIT. Part of this work was supported by CSIR-XII five year plan network project (SETCA; CSC-0113) and SAHYOG-EU-FP7-KBBE funded by DBT (No. BT/IN/EU/07/PMS/2011).

\section{REFERENCES}

[1] I. Velghe, R. Carleer, J. Yperman, and S. Schreurs, "Study of the pyrolysis of municipal solid waste for the production of valuable products," J. Anal. Appl. Pyrol., vol. 92, pp. 366-375, 2011.

[2] Z. Hu, W. R. G. Saman, R. R. Navarro, D. Wu, D. Zhang, M. Matsumura, and H. Kong, "Removal of PCDD/Fs and PCBs from sediments by oxygen free pyrolysis," J. Environ. Sci., vol. 18, pp. 989-994, 2006.

[3] C. R. Anderson, L. M. Condron, T. J. Clough, M. Fiers, A. Stewart, R. A. Hill, and R. R. Sherlock, "Biochar induced soil microbial community change: Implications for biogeochemical cycling of carbon, nitrogen and phosphorus," Pedobiologia, vol. 54, pp. 309320, 2011.

[4] A. Cross and S. P. Sohi, "The priming potential of biochar products in relation to labile carbon contents and soil organic matter status," Soil Biol. \& Biochem., vol. 43, pp. 2127-2134, 2011.

[5] S. Jeffery, F. G. A. Verheijen, M. van der Velde, and A. C. Bastos, “A quantitative review of the effects of biochar application to soils on crop productivity using meta-analysis," Agri. Ecosys. Environ., vol. 144, pp.175-187, 2011.

[6] M. Zhang and B. Gao, "Removal of arsenic, methylene blue and phosphate by biochar/AlOOH nanocomposite," Chem. Engg. J., vol. 226, pp. 286-292, 2013.

[7] M. Wang, C. Wang, M. Chen, Y. Wang, Z. Shi, X. Du, T. Li, and Z. $\mathrm{Hu}$, "Preparation of high-performance activated carbons for electric double layer capacitors by $\mathrm{KOH}$ activation of mesophase pitches," New. Carbon. Mat., vol. 25, pp. 285-290, 2010.

[8] M. Agarwal, J. Tardio, and S. V. Mohan, "Critical analysis of pyrolysis process with cellulosic based municipal waste as renewable source in energy and technical feasibility," Bioresour. Technol., vol. 147, pp. 361-368, 2013.

[9] C. Agudelo, M. Lis, and J. Valldeperas, "Fabric color changes in polyster microfibers caused by the multiple reuse of dispersed-dyes dye baths: part 1," J. Text. Res., vol. 78, pp. 1041-1047, 2008.

[10] S. M. Burkinshaw, J. Howroyd, N. Kumar, and O. Kabambe, "The wash-off of dyeing using interstitial water: part 3 Disperse dyes on polyster," Dyes. Pigm., vol. 91, pp. 340-349, 2011.

[11] S. V. Mohan, N. C. Rao, and J. Karthikeyan, "Adsorptive removal of direct azo dye from aqueous phase onto coal based sorbents - a kinetic and mechanistic study," J. Haz. Mat., vol. 90, pp. 189-204, 2002.

[12] S. Venkata Mohan, P. Sailaja, M. Srimurali, and J. Karthikeyan, "Color removal of monoazo acid dye from aqueous solution by adsorption and chemical coagulation," Environ. Engg. Policy., vol. 1, pp. 149-154, 1999.

[13] C. Namasivayam and R. T. Yamuna, "Removal of congo red from aqueous solutions by biogas waste slurry," J. Chem. Tech. Biotechnol., vol. 53, pp. 749-758, 1992.

[14] I. D. Mall and S. N. Upadhyay, "Removal of basic dyes from wastewater using boiler bottom ash," Indian J. Environ. Health., vol. 37, pp. 1-10, 1995.

[15] S. Venkata Mohan, S. V. Ramanaiah, and P. N. Sarma, "Biosorption of direct azo dye from aqueous phase onto spirogyra sp. 102. Evaluation of kinetics and mechanistic aspects," Biochem. Engg. J., vol. 38, pp. 61-69, 2008.

[16] M. Agarwal, J. Tardio, and S. Venkata Mohan, "Biohydrogen production from kitchen based vegetable waste: Effect of pyrolysis temperature and time on catalysed and non-catalysed operation,' Bioresour. Technol., vol. 130, pp. 502-509, Feb. 2013.

[17] A. K. Kumar, S. V. Mohan, and P. N. Sarma, "Sorptive removal of endocrine disruptive compound (estriol, E3) from aqueous phase by batch and column studies: kinetic and mechanistic evaluation," $J$. Haz. Mater., vol. 164, pp. 820-828, 2009.

[18] S. V. Mohan and J. Karthikeyan, "Removal of lignin and tannin aqueous solution by adsorption onto AC," Environ. Pollut., vol. 97, pp. 183-187, 1997
[19] M. Yalcin, A. Gurses, C. Dogar, and M. Sozbilir, "The adsorption kinetics of cethyltrimethylammonium bromide (CTAB) onto powdered active carbon," Adsorption, vol. 10, pp. 339-348, 2004.

[20] M. U. Dural, L. Cavas, S. K. Papageorgiou, and F. K. Katsaros, "Methlene blue adsorption on activated carbon prepared from Posidonia oceania (L.) dead leaves: Kinetics and equilibrium studies,' Chem. Engg. J., vol. 168, pp. 77-85, 2011.

[21] A. K. Kumar and S. V. Mohan, "Endocrine disruptive synthetic estrogen (17 $\alpha$-ethynylestradiol) removal from aqueous phase through batch and column sorption studies: Mechanistic and kinetic analysis," Desalination, vol. 276, pp. 66-74, 2011.

[22] X. Yang and B. A. Duri, "Kinetic modeling of liquid-phase adsorption of reactive dyes on activated carbon," J. Colloid Interface Sci., vol. 287, pp. 25-34, 2005.

[23] S. V. Mohan, S. Shailaja, M. R. Krishna, and P. N. Sarma, "Adsorptive removal of phthalate ester (di-ethyl phthalate) from aqueous solution by activated carbon: A kinetic study," J. Haz. Mat. vol. 146, pp. 278-282, 2007.

[24] E. Bulut, M. Ozacar, and I. A. Sengil, "Adsorption of malachite green onto bentonite: equilibrium and kinetic studies and process design," Microporous Mesoporous Mater., vol. 115, pp. 234-246, 2008.

[25] F. Wu, R. Tseng, and R. Juang, "Characteristics of Elovich equation used for the analysis of adsorption kinetics in dye-chitosan systems," Chem. Engg. J., vol. 150, pp. 366-373, 2009.

[26] H. Teng and C. Hsieh, "Activation energy for oxygen chemisorptions on carbon at low temperatures," Ind. Eng. Chem. Res., vol. 38, pp. 362-371, 1999.

[27] I. Langmuir, "The adsorption of gases on plane surfaces of glass, mica and platinum," J. Am. Chem. Soc., vol. 40, pp. 1361-1403, 1918.

[28] J. S. Piccin, C. S. Gomes, L. A. Feris, and M. Gutterres, "Kinetics and isotherms of leather dye adsorption by tannery solid waste," Chem. Engg. J., vol. 183, pp. 30-38, 2012.

[29] H. M. F. Freundlich, "Over the adsorption in solution," J. Phys. Chem., vol. 57, pp. 385-470, 1906.

[30] M. I. Temkin and V. Pyzhev, "Kinetics of ammonia-synthesis on promoted iron catalysts," Acta Physiochem. URSS, vol. 12, pp. 327 $356,1940$.

[31] R. Sips, "Combined form of Langmuir and Freundlich equation," $J$. Chem. Phy., vol. 16, pp. 490-495, 1948.

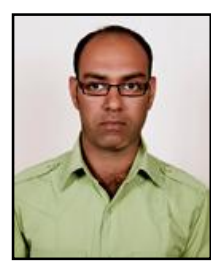

Manu Agarwal was born on January 5, 1985. Manu Agarwal received his B.Tech. degree in chemical engineering from JNTU, Hyderabad, Andhra Pradesh, India in 2006 and M.Tech. degree in chemical engineering from IIT Roorkee, Roorkee, Uttarakhand, India in 2008.

$\mathrm{He}$ is currently a $\mathrm{PhD}$ student at RMIT University. He has two publications to his credit. Mr. Agarwal is a life time associate member of IIChE.

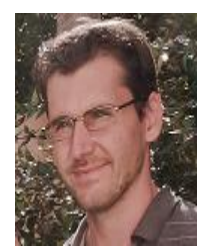

James Tardio was born on August 9, 1973. Dr. James Tardio received his bachelor degree of science (honours) from The University of Melbourne in 1996 and a PhD degree in industrial chemistry from RMIT University in 2002.

$\mathrm{He}$ is currently a senior lecturer in the School of Applied Sciences at RMIT University and the resources theme leader for the Centre for Advanced Materials and Industrial Chemistry. His research interests include minerals processing, treatment of waste water / industrial effluents and catalysis. Dr. James is currently the victorian representative for the Royal Australian Chemical Institutes Industrial Chemistry division.

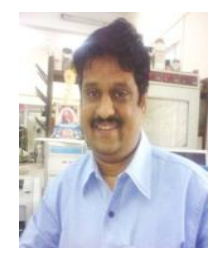

S. Venkata Mohan was born on July 1, 1970. Dr. S Venkata Mohan received his B.Tech. degree in civil engineering from Sri Venkateswar University, Tirupati, India in 1991, M.Tech. degree in environmental engineering from Sri Venkateswar University, Tirupati, India in 1993 and PhD degree in environmental engineering from Sri Venkateswar University, Tirupati, India in 1998.

$\mathrm{He}$ is currently a principal scientist in CSIR-Indian Institute of Chemical Technology, Hyderabad, India. He has more than 200 publications, six patents and 24 book chapters. His main research interests are in the domain of environmental biotechnology and bioenergy.

Dr. Mohan was elected fellow of Biotech Research Society of India (FBRSI), and Andhra Pradesh Akademy of Sciences (FAPASc). Dr Mohan was the recipient of 'National Bioscience award-2012' by DBT, Government of India. 